Amazônia brasileira 



\title{
Bases para o estudo dos ecossistemas da Amazônia brasileira
}

\author{
AZIZ N. AB'SABER
}

$\mathrm{U}$ MA REFLEXÃO mais demorada sobre os ecossistemas ocorrentes no domínio morfoclimático e fitogeográfico da Amazônia brasileira guarda um interesse científico e didático. $\mathrm{O}$ fato de a região ter sido apresentada sempre como o império das florestas equatoriais, de disposição zonal, acarretou distorções sérias nos estudos dos ecossistemas regionais. É certo que, em termos do espaço total amazônico, predominam esmagadoramente os ecossistemas de florestas dotadas de alta biodiversidade. Entretanto, se levarmos em conta o conceito original de ecossistema, independentemente das disparidades espaciais de sua ocorrência, chegaremos a um número bem maior de padrões ecológicos locais ou sub-regionais.

Antevistos pelo critério de sua especificidade - suporte ecológico e padrão de biodiversidade - pode-se agrupar os ecossistemas ocorrentes em três categorias:

- Ecossistemas contrastados de "terras firmes" (tipo enclaves de cerrados, ilhados no meio das grandes matas), somente explicáveis pela Teoria dos Refúgios;

- Diferenciações intra-florestais, pela presença de manchas de areia branca em terraços, várzeas e interflúvios arenosos, ou pela demorada presença de água de transborde em planícies de rios sujeitos a fortes oscilações de nível (respectivamente, tipos campinarana e campinas, e tipo igapó);

- Ecossistemas extremantes localizados, originados por mini-refúgios nas paredes de "pães-de-açúcar" e lajedos, ou seu entorno; ou ocorrentes em ingremes barrancas de abrasão fluvial, atualmente sujeitas a (re)florestamento (tipo "pontões" rochosos de Roraima, em Mucagaí; ou altas barrancas do Amazonas, em Monte Alegre). Evidentemente, não fossem os estudos aproximativos sobre a história vegetacional da Amazônia brasileira, realizados no ensejo dos trabalhos que deram respaldo à Teoria dos Refúgios, seria difícil ou quase impossível explicar as manchas de cerrados e campestres regionais, ou a ocorrência de cactos nos "pedrões" de Roraima ou nas barrancas de Monte Alegre.

No que se refere às planícies aluviais, a variedade dos ecossistemas é muito grande, tal é o dédalo do mosaico terra-água, sobretudo no caso do médio e baixo Amazonas. Na larga planície de 14 a 35 quilômetros de largura, sucedem-se e 
se repetem faixas anastomosadas de ecossistemas no meio dos numerosos setores deprimidos ou ligeiramente "altos" da rasa planície. Pouca gente sabe que o rio Amazonas, nos setores considerados, é um dos cursos d'água que transporta a maior carga de sedimentos finos em solução, acrescidos de minitouceiras de vegetação flutuante, na face da Terra. $\mathrm{O}$ contraste entre as águas escuras do rio $\mathrm{Ne}$ gro face as águas amarelo-pardacentas do Solimões/Amazonas indica atributos hidrobioquímicos e hidrogeomorfológicos.

Para quem faz pesquisas nos confins de Mato Grosso, no extremo norte de Tocantins ou no centro do Maranhão é fácil saber onde começa a Amazônia. Quando as florestas deixam de ser apenas galerias amarradas ao fundo aluvial dos vales; quando as matas sobem e fecham as vertentes e interflúvios das colinas onduladas, onde antes, para o sul, o sudeste e o leste existiam extensos cerrados; ou, ainda, quando cerrados e matas secas cedem lugar para intermináveis florestas de "terra firme": aí começa a Amazônia. Em várias faixas de contato entre cerrados e matas na periferia da Amazônia ocorrem mosaicos complexos de paisagens de retalhos de chapadões ou baixo platôs com cerrados, e colinas onduladas e serrinhas com matas de "terra firme" ou orográfica. Maior complexidade ainda ocorre quando existem campestres pontilhados de arboretos dos cerrados (Roraima), passando gradualmente para matas de terra firme (Mucapai, Caracas) ou campos cerrados transicionando para matas orográficas (centro-oeste de Roraima, centro-sul do Amapá). A rigor, em todas as grandes manchas de campestres ou cerrados que se estendem ao norte do rio Amazonas - a saber, campos de Boa Vista, cerrados de Monte Alegre, cerrados naturalmente degradados do Amapá - ocorrem contatos complicados entre as formações abertas e o início das grandes matas que as envolvem.

O Negro praticamente não tem planícies aluviais: estende-se de barreira a barreira, ou de talude de terraço até as barrancas da outra banda. Em frente de Manaus, o rio chega a atingir 22 quilômetros de largura. Mas, em compensação, apresenta dois notáveis setores de restingas fluviais síltico-argilosas centrais, fixadas por um ecossistema de florestas baixas, pouco diversificadas. Dir-se-ia que existem dois arquipélagos fluviais - tipo anavilhanas - no rio Negro: um, a montante de Manaus, outro a montante da barra do rio Branco com o Negro, conforme foi detectado no Projeto RADAM. Uma das poucas hipóteses razoáveis para ex-plicar a gênese dessas duas "anavilhanas" é que, durante o tempo de águas baixas e muito menos volumosas do Pleistoceno terminal (entre 23 e 13 mil anos A.P. - antes do presente), o rio teria tido dois canais laterais locais e um espécie de plataforma provisória e exposta, reinvadida pelas águas durante os últimos 12.700 anos, ao ensejo da densificação das florestas devido o gradual e quase contínuo aumento das precipitações pluviais na alta bacia do Negro/Vaupés. A fímbria estreita de terraços arenosos eventualmente existente na beira do tabuleiro de Manaus talvez tenha se formado durante os impactos pedológicos e climáticos do otimo climaticum. Mesmo que não existam largas e continuas planícies 
aluviais no baixo rio Negro, ocorrem diversos ecossistemas diferenciados na região de Manaus: matas baixas, das anavilhanas; igapós a partir dos diques marginais engastados na beira alteada rio Negro; buritizais e buritiramas e outras palmáceas em faixas deprimidas dos tabuleiros regionais; campinas e campivaranas em terraços de areia branca ou manchas arenosas mal pedogenizadas de interflúvios; e, por fim extensas florestas biodiversas de "terra firme".

No caso particular da larga e longa planície amazônica, desde a barra do rio Negro até as proximidades do golfão Marajoara, o desdobramento dos ecossistemas da própria faixa de aluviação é extraordinário. O Amazonas permanece centralizado no meio da grande planície que construiu ou (re)elaborou no decorrer do Holoceno. O rio se destaca bem no meio das terras baixas, parcialmente submersíveis, embutidas entre tabuleiros. Aqui não é o rio que se estende de "barreira" a "barreira" da outra margem. Sem a sua planície aluvial, o rio tem de quatro a seis quilômetros de largura; a planície que ele elaborou por processos hidrogeomorfológicos possui de 14 a 35 quilômetros de extensão lateral. Trata-se de um mosaico terra-água labiríntico, extremamente diversificado: diques marginais baixos outrora florestados, ultrapassados pelas águas durante as grandes cheias; florestas de várzeas altas em alguns setores em que a planície encosta-se na base dos tabuleiros; réstias de florestas biodiversas em diques marginais interiorizados; campinas em volutas de areia branca de riachos meândricos já desaparecidos; vegetação herbácea ou campestre em leitos abandonados; capins nativos nas bordas de lagos de várzea, expostos ou submersos, em função da retração ou re-expansão das águas. E, por fim, uma assimetria berrante de ecossistemas nas margens dos paranás, em um caso em que florestas de terra firme recobrem tabuleiros, barrancas altas ou taludes de terraços da banda interna dos aludidos canais laterais descontínuos (os falsos rios dos franceses; o yazoo river dos norte-americanos), enquanto da outra banda estende-se uma multidão de ecossistemas terrestres, aquáticos e subaquáticos das planícies aluviais labirínticas. Na faixa desse verdadeiro mosaico terra/águas, interposta entre o Paraná e o rio Amazonas propriamente dito, ocorrem ecossistemas muito diferenciados entre si, ainda que pertencentes a uma só família do ponto de vista hidrogeomorfológico.

Somente quem viajou por esses canais laterais naturais - designados paranás - pode avaliar a sua largura e profundidade relativa. Daí porque navios de certo porte podem navegar nas tranqüilas águas dos paranás. Alguns dentre eles como é o caso do agigantado paraná do Ramos - estendem-se por dezenas a centenas de quilômetros. Muitos dos afluentes da margem direita ou esquerda do Amazonas, antes de lançarem suas águas no grande rio, deságuam em setores dos paranás ou embaiamentos d'água similares, devido ao bloqueio feito por restingas fluviais. Disso resulta que as próprias águas dos paranás sejam diferentes que as do Amazonas, rio de longo curso, acumulador progressivo de sedimentos argilosos e sílticos. 


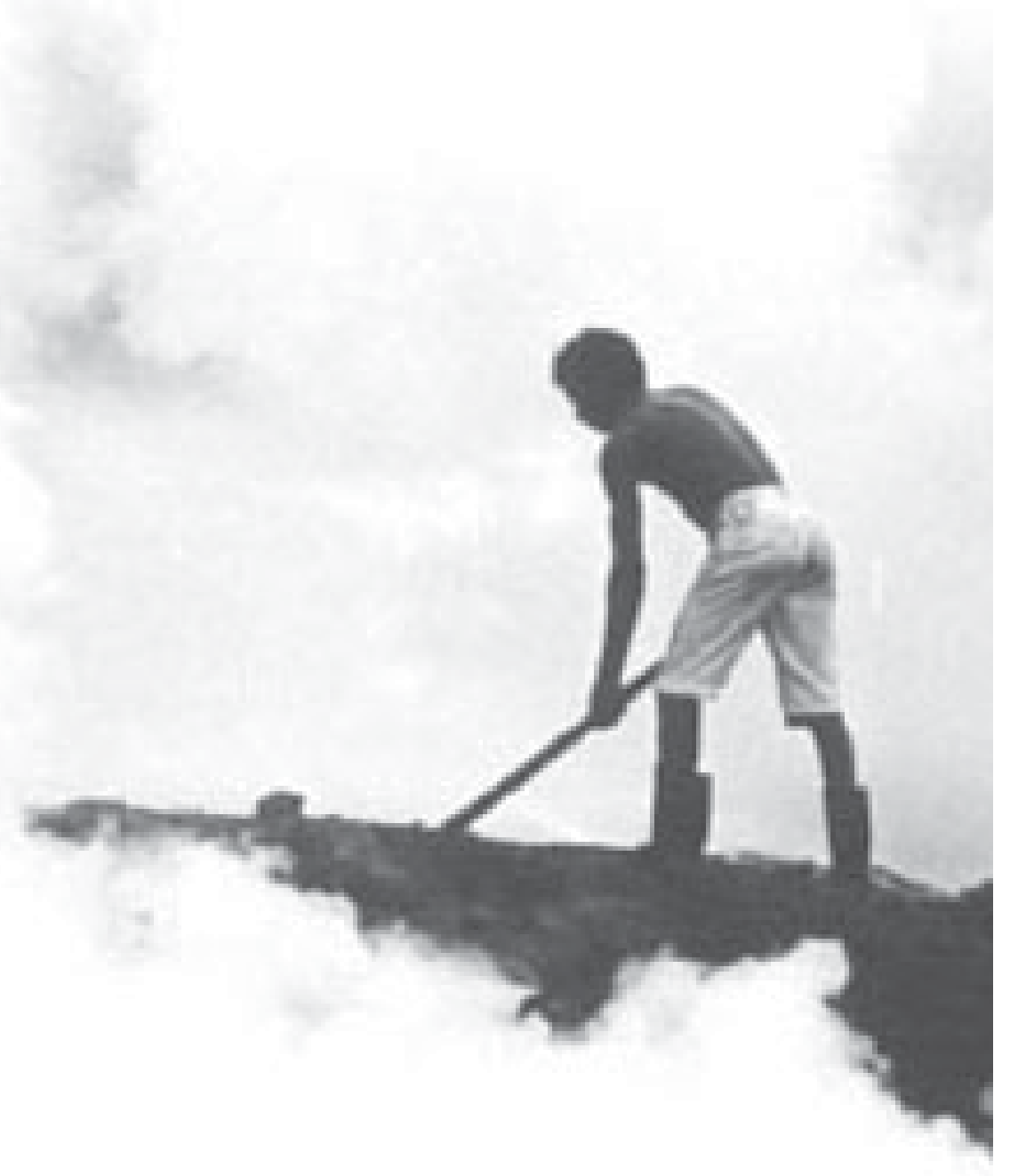




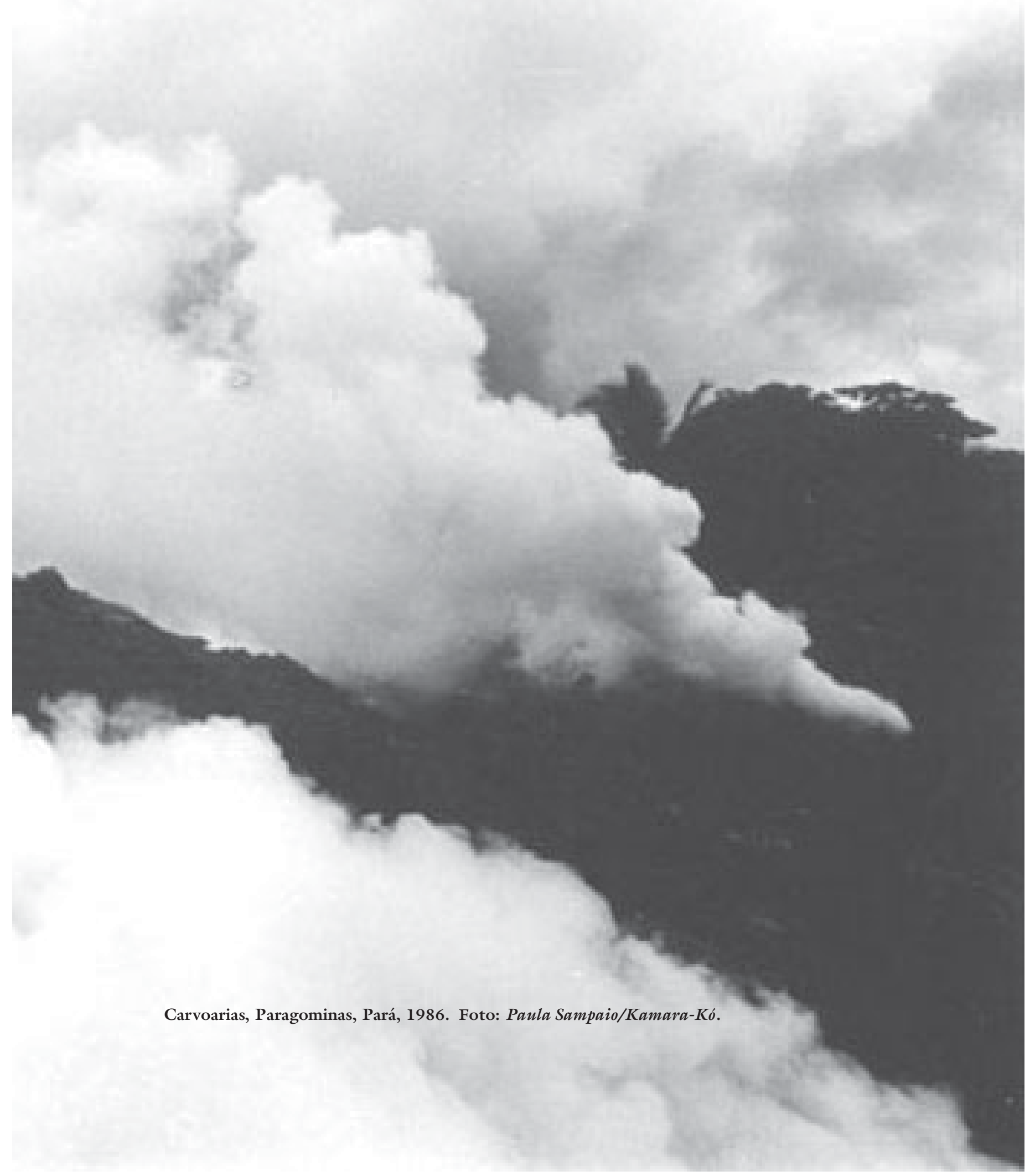




\section{Variações internas na composição dos ecossistemas florestais amazônicos: laterais e altitudinais}

Além dos padrões mais contrastados de ecossistemas encontrados na Amazônia brasileira (matas, cerrados, campinas, mini-reliatos de cactáceas), ocorrem diversificações sutis na composição biótica do grande contínuo florestal regional. Trata-se de transições complexas, compreensíveis quando ocorrentes do centro para as periferias extremas, porém mais difícil de serem entendidas quando incidentes nas próprias áreas centrais do domínio morfoclimático e fitogeográfico da Amazônia. No que tange às variações altitudinais, tínhamos melhores parâmetros para entendê-las devido as variações sutis entre a flora das matas de sopés e grotões e aquela dos "altos", localizadas nos trechos planálticos do reverso continental da serrania.

Em termos puramente fitogeográficos genéricos, e não especificamente botânicos, existem diversas estratégias para se perceber as diversificações internalizadas no grande contínuo das matas amazônicas. O primeiro desses critérios diz respeito à identificação da biodiversidade regional, que é pan-amazônica, em face das espécies que são específicas de um só quadrante ou de poucas sub-regiões muito separadas entre si na bastidão das terras florestadas da Amazônia. Outro critério importante está relacionado com a observação das espécies dominantes no sub-bosque de certos e determinados trechos das florestas. Um terceiro critério diz respeito à identidade e cartografação de faixas de "matas de cipó", que envolvem trechos de matas densas, em forma linear ou semi-circular. Em um estudo geomorfológico sobre a serra dos Carajás, identificamos, de passagem, uma chave inusitada para detectar rapidamente diferenças de composição das porções basais e de cimeira das áreas de florestas arográficas: através da observação de espécies que crescem nas capoeiras pioneiras de pequenas áreas devastadas - ainda que nos altos da serra dos Carajás existam ecossistemas relutais, berrantemente contrastados, constituídos por cactos e orquídeas arcaicas, fixadas em bordas de cangas ferríferas, além de clareiras arbustivas de espécies relativamente homogêneas, em vertentes de colinas dotadas de solos rasos, extremamente pobres. Para não falar das veredas que envolvem o trecho montante terminal de florestas de galerias, de exceção, existentes nas cimeiras relativamente planas da serra.

Municiados por tais estratégias metodológicas, além de outras que a elas venham se acrescentar, pode-se chegar a uma aproximação mais lógica do extraordinário mosaico de ecossistemas da Amazônia, sendo que o conjunto desses critérios-chave tem condições de aplicabilidade garantida para outros setores da Amazônia, vistos como macro-espaços no interior da América tropical. Ou seja, são aplicáveis com modificações e acréscimos às terras amazônicas, em nível sulamericano.

\section{Diversificação sub-regional de ecossistemas na Amazônia brasileira}

Do que se conhece das margens e terminações das florestas amazônicas, pode-se afiançar que as maiores diversificações ecossistêmicas são encontradas 
entre os Parecis e o Grande Pantanal Mato-grossense, na faixa oeste-leste do Maranhão, e, sobretudo, em diferentes quadrantes do estado da Roraima. Em todos esses casos, as baixas de transição e contato dependeram da compartimentação topográfica regional e das flutuações climáticas quaternárias sofridas por essas áreas, tão distantes entre si.

Num transecto norte-sul, desde o alto e médio rio Arinos até o Pantanalpassando pela chapada dos Parecis e a depressão intermontana colinosa de Cuiabá - encontra-se um tipo de terminação dos mais complexos de todo o mundo tropical brasileiro. Os depósitos retidos na bacia do Pantanal possibilitam uma boa compreensão dos acontecimentos palioclimáticos e paleoecológicos, assim como de fatos relativos à neotectônica, que se sucedem na depressão do alto Paraguai, no decorrer do Quaternário (Ab'Saber, 1988).

As modificações paisagísticas, ecológicas e de zoneamento climático ocorrentes ao longo do Maranhão ocidental, Piauí e Ceará constituem, por sua vez, todo um esquema de faixas de transição e contatos, incluindo faixas de ecótonos na periferia das florestas amazônicas (sem solução de continuidade) - transição e contato brusco entre as florestas do planalto Maranhense com a zona dos Cocais da baixada costeira regional. E, ao leste do planalto - desde as proximidades de Barra do Corda até o vale do Parnaíba, com suas extensas matas de galerias coalhadas de babaçu - estendem-se campos cerrados, os quais, após pequenos enclaves de semi-aridez (Campo Maior), sobem pelas rampas do reversos de cuestas do Piauí, sob a forma entreverada de cerrados/caatingas, constituindo-se em um dos ecótonos mais rusticamente expressivos do país. Não é preciso destacar a imensa variedade de ecossistemas existentes entre as florestas do Maranhão centro-ocidental (matas dos "avanrandados") e os sertões colinosos e rebaixados do Ceará, a leste da serra Grande do Ibiapaba.

No momento, porém, interessa-nos elaborar uma síntese dos conhecimentos palioclimáticos e paleo-ecológicos de Roraima, em um momento em que se conhece melhor a compartimentação topográfica e as formações detríticas de seu espaço fisiográfico total.

No espaço fisiográfico do estado de Roraima, ocorre a nordeste uma pequena bacia sedimentar arenosa do Quaternário médio ou inferior, embutida em uma área deprimida originada por uma neotectônica pós-pliocênica. Os sedimentos da bacia de Boa Vista são fluviais ou flúvio-lacustres rasos, expostos a algumas dezenas de metros acima do nível das águas do rio Branco. Não conhecemos muita coisa da espessura média dos seus depósitos, mas podemos adiantar que sua base deve ser relativamente irregular no contato com rochas précambrianas ou vulcânicas modernas. Em termos de ecossistemas - até onde se estendem os campos do rio Branco, pontilhados por espécies não muito diversificadas de cerrados - predominam padrões de campestres, florestas de galerias marcadas por notáveis rengues de buritis e alguns raros relictos de cerrados em franco processo de degradação. No entorno da bacia de Boa Vista, em áreas fortemente compartimentadas, ocorrem alternâncias de campos com florestas 
submontanas, eventuais "pontões" ou "padrões" rochosos comportando minirelictos de cactáceas. A oeste, noroeste e norte-nordeste, estendem-se continuamente florestas orográficas e alta-montanas até a larga faixa de fronteiras com a Venezuela. Ao norte, após transpor frágeis florestas orográficas, atinge-se os campestres de cimeira do planalto das Guianas, conhecidos por gran sabana (entre BV 8, Brasil, e Santa Helena de Ouraen, Venezuela). Em prosseguimento, em pleno território venezuelano, ocorrem os montes testemunhos ruineformes dos tepuis, os quais quebram a monotonia dos espaços campestres da gran sabana. $\mathrm{Na}$ fronteira tríplice do Brasil, Venezuela e República Comunitária da Guiana, os picos da Roraima e do Caburaí, com altitudes tangentes a 2.900 metros, apresentam cabeças rochosos emergindo acima das florestas orográficas, expondo paredes rochosas, lajedos e blocos das mais variadas formas, constituindo-se em ecossistemas rupestres locais (rupestres-biomas).

Nas terras baixas, ao sul dos campos de Boa Vista, na área drenada pelo baixo Rio Branco e alguns de seus afluentes meridionais (Juaperi e Catrimani), existe um mosaico complicado de matas de galerias, campos varzeanos e inesperados campos de dunas (Schneider, 1994). O mosaico matas/campos inicia-se aproximadamente na região de Mucajaí e consolida-se nas terras firmes existentes ao sul de Caracaraí. Mas, logo, quando o rio Branco se aproxima de sua barra no rio Negro, encontra a depressão mais pronunciada de toda a Roraima, envolvendo diques marginais florestados, várzeas submersíveis e os subconjuntos dunosos de areia branca elaborados em algum estágio do Pleistoceno terminal, ou, até mesmo do Holoceno, a partir do retrabalhamento de áreas retiradas de rio acima, sobretudo da formação Boa Vista, segundo tudo leva a crer.

Referimos tais condições de sedimentação, ocorrentes na bacia do baixo rio Branco e nas planícies coalescentes de seus afluentes meridionais, porque se trata nitidamente de uma outra assembléia de ecossistemas locais da Amazônia, devido a presença de suportes ecológicos bizarros - inclusive com a presença de dunas, conforme os estudos pioneiros de Schneider e seus companheiros de pesquisas. Na realidade, o baixo rio Branco é uma das duas regiões deprimidas existentes no espaço geomorfológico total do estado de Roraima. A primeira dessas depressões situa-se a nordeste do estado, expressando-se por um relevo colinoso e solos predominantemente arenosos.

Ela foi gerada ao norte do baixo platô terciário de Manaus, em um paleoespaço de desnudação marginal acompanhado de ligeira eversão e sujeito a uma subsidência bastante moderada, porém suficiente para dar origem à pequena bacia sedimentar designada formação Boa Vista. A segunda região deprimida está bem longe das colinas e campos de Boa Vista, ampliando-se na área do baixo rio Branco. É uma legítima planície de coglescência aluvial dos diversos rios afluentes que ali se concentram, já muito próximo da barra do rio Branco sobre o rio Negro. Estreitos diques marginais florestados, planícies de inundação sincopadas dotadas de campos de várzeas e conjuntos de dunas de areia branca, semi-fixados ou semi-ativos, amontoam nessa planície, dando origem ocasional a psamo-biomas. 


\section{Aplicação do conceito de ecossistema à Amazônia pan-americana}

A Amazônia é a região ideal para o reconhecimento de ecossistemas, nos termos que Tansley (1935) propôs para a identificação dos tipos de sistemas ecológicos naturais existentes em um determinado território. O criador dessa expressão era botânico de origem, mas ao rever a história das ciências ecológicas atingiu um noção interdisciplinária, fora do comum, em relação aos cientistas por demais atrelados aos métodos e objetivos de uma só e mesma disciplina. Tansley, ao contrário, propugnou pelo estudo integrado de todos os fatos que criam suporte para o desenvolvimento de biotas adaptadas a viver em determinados locais. Portanto, considerava a trama local dos fatos abióticos - pedológicos, hídricos e climáticos - que servem de suporte ecológico para a existência de um determinado contigente de vida vegetal e animal observável em um pequeno espaço, independente de sua área de extensão total e dos ecossistemas de seu entorno. Para efetivar tal estado na prática, indica-se sempre o método dos "quadrantes".

Na história da difusão do conceito entre comunidades científicas do mundo inteiro, aconteceram retardos lamentáveis, acrescidos de interpretações aleatórias, distorções e reducionismos perigosos. A frase que mais comumente se dizia - "um ecossistema é o conjunto de fatos abióticos e bióticos de um determinado local" - era por demais sintética e didaticamente impotente. Sobretudo porque um dos fatos tidos como abióticos está profundamente entranhado de microorganismos, elementos graxos, raízes decompostas, materiais biogênicos provindos da serrapilheira e colóides: referimo-nos, evidentemente, aos solos de cada ponto, sub-área ou região natural da superfície terrestre. Na realidade, os solos constituem tipos de tecidos, formados pela decomposição ou alteração superficial de rochas de cada área ou região. São, na maior parte das vezes, reelaborados pela coluviação, aluviação sazonal, infiltração e evaporação estacional de águas, e pela presença de microorganismos, nutrientes minerais, animais fuçadores, colóides de componentes graxos e matéria orgânica oriunda da deterioração das raízes e da porção basal do folhedo (horizonte $\mathrm{A}$ ).

Outro fator de apoio para o desenvolvimento e permanência da vida vegetal em um certo espaço, onde foi ou está sendo "fabricado" um tipo de solo, é a dinâmica climática regional e local. $\mathrm{Na}$ realidade, os processos de fotossíntese auto-sustentadores da vida vegetal, assim como o fornecimento de águas para a hidratação dos solos e das plantas, dependem da associação entre o calor, a umidade e as chuvas, entrosados com a luminosidade e a energia solar, em seus cursos de atuação diária e estacional. É uma história vegetacional que remonta aos fins do Cenozóico, sensu stricto, e que envolveu a multiplicação da biodiversidade no decorrer do Quaternário, incluindo retrações e re-expansões dos diferentes tipos de vegetação, sob uma constante competição pela luminosidade e pela interação entre calor e umidade. Esses são os fatores básicos que explicam o complexo quadro dos ecossistemas amazônicos. 
Por uma tendência de simplificação didática errada, muitos autores preferem filiar-se à idéia de que um ecossistema tem que ser conhecido em sua estrutura e em sua funcionalidade. A despeito de seu grande interesse biogeográfico, tal enfoque, quando se pretende espacializar os ecossistemas predominantes em um certo território, vale muito pouco para se entender a totalidade de um ecossistema. Isso porque, entre o estudo prévio da estrutura e a tentativa de compreender a funcionalidade em nível sinecológico, resta a imensa tarefa de identificar a composição biótica do sistema ecológico em nível de um pequeno espaço representativo. Dessa forma, o estudo integrado verdadeiro de um ecossistema intertropical, por exemplo, não se esgota nunca, devido à dificuldade de encontrar equipes polivalentes, capazes de identificar o complexo mundo biótico representado pela vegetação, fauna e estoque microorgânico ativo dos solos e das serrapilheiras. Mas nem por isso os pesquisadores interessados no estudo dos ecossistemas de uma região qualquer devem desanimar, sobretudo quando se trata da enorme complexidade dos sistemas ecológicos do mundo tropical. Todos podem colaborar, dentro de sua especialidade, para se compreender uma das "faces" de um ecossistema, visto na escala de um pequeno espaço representativo. E, nesse sentido - pelas razões expostas na presente contribuição - a Amazônia é a região do mundo que apresenta o maior número de espaços ecológicos representativos, dispostos desde as vertentes cisandinas até as intermináveis colinas e tabuleiros florestados, grandes planícies aluviais e serranias intra-amazônicas de Roraima ocidental e dos Carajás. Enfim, desde as altas encostas chuvosas dos Andes peruanos e colombianos até os manguezais, furos e gamboas do litoral do Amapá, Pará e noroeste do Maranhão.

\section{Os ecossistemas da fachada atlântica da Amazônia brasileira: a multiplicação de suportes ecológicos}

O estudo do feixe de ecossistemas que marcam a originalidade da fachada atlântica da Amazônia brasileira constitui-se em uma tarefa à parte nos estudos sobre a zona equatorial de nosso país. $\mathrm{O}$ fator número um responsável pela constituição do suporte ecológico da faixa litorânea do Amapá, de Marajó (Pará) e do nordeste paraense e maranhense está relacionado com o extraordinário volume de sedimentos finos que o rio Amazonas descarrega nas águas do golfão Marajoara: o mar Dulce dos antigos cronistas. Na realidade, porém, uma parte importante desses sedimentos argilosos é devolvida para a beira dos estuários e margens terminais de alguns rios de maior porte. O leque de lamas que se forma em frente de Marajó graças à junção do material fino descartado pelas boca norte do Amazonas e a boca do rio Pará (Tocantins, estreitos de Breves, rio Guamá) ficou disponível para a ação das marés, em uma costa marcada por uma tropicalidade berrante. Daí decorre as duas modalidades de mangues da costa do Amapá e do litoral do Pará-Maranhão. Trata-se de manguezais frontais, fisiograficamente muito diferentes entre si: retilinizados no Amapá, após o delta do Araguarí, e “trombetiformes" na zona costeira do nordeste paraense e noroeste do Maranhão, 
não existindo nada igual no restante da costa tropical e subtropical atlântica do Brasil.

Para se entender corretamente a gênese da zona costeira amazônica, é necessário recorrer aos conhecimentos sobre o "sobe e desce" do nível do oceano e suas conseqüências regionais. Sabe-se que entre 23 e 13 mil anos A.P., o nível dos mares baixou para aproximadamente 100 metros. Nesse período de tempo, os climas da Amazônia comportavam precipitações menores do que as atuais e uma sazonalidade pronunciada, enquanto o rio, por razões óbvias, era ele próprio menos volumoso. Foi esse rio ligeiramente emagrecido que se estendeu gradualmente até a linha da costa rebaixada e recuada. Devido à mudança do nível da base e à atuação forte da erosão regressiva, formaram-se canyons na plataforma continental, secionando os terraços elaborados em períodos mais antigos (Pleistoceno médio e pro-parte Superior). Vale dizer que a erosão regressiva de grande extensividade no interior do eixo principal do Amazonas e baixos vales de seus afluentes secionou os terraços baixos mantidos por cascalhos (terraços de Icoaraci, Macapá) e o desvão de revelo onde hoje se localiza o delta interno de Breves.

Quando o mar subiu, a partir de 12.700 anos A.P., atingindo um nível aproximado de 3 metros acima da atual, provocou um extraordinário afogamento ao longo dos emboques norte e sul do Amazonas, dando origem a um largo canal na retro-terra de Marajó (paleo-canal de Breves, segundo propomos). Durante sua ascensão, o mar à frente da terra firme marajoara executou um processo abrasivo fundo, que hoje está muito bem marcado, em uma linha norte-sul, na porção centro-oriental da ilha. Até aquele momento inexistiam as planícies costeiras que hoje aparecem no Amapá, no leste-nordeste do Marajó, no nordeste do Pará e no noroeste do Maranhão. Em um "desce e sobe" de baixa amplitude - mensurável em metros - o mar recuou de sua linha de costa paleo-marajoara, iniciando os processos de sedimentação que criaram suportes ecológicos para os atuais campos inundáveis de Marajó. Tais acontecimentos proporcionaram sedimentação argilosa, que se tornou frontal além da delta do Araguarí, na direção do pontal do Oiapoque, e "trombetiforme" à frente e nos bordos das "rias" sucessivas.

Quando o nível do mar atingiu 3 metros acima do nível do mar, entre 6 e cinco mil A.P., por ocasião do optimum climático, as águas marinhas, com salinidade atenuada, envolveram a porção ocidental da terra firma marajoara, fazendo recuar a condição de estuários para o baixo Tocantins e o baixo Amazonas. O cenário dessa época pressupunha largos canais semi-marinhos e embaiamentos através das duas bocas encurtadas já estabelecidas ao norte e ao sul da terra firme centroocidental de Marajó. Entretanto, a porção oriental da ilha estava submetida a uma ingressão rasa, de forte atuação abrasiva, preparando assim a plataforma baixa que viria a receber a sedimentação mais recente que caracteriza a complicada região dos campos submersíveis de Marajó. E incluindo ainda, mascaradamente, a linha de costa interiorizada da paleo-enseada do bordo oeste do lago Ararí. O recuo do mar por meio de irregularidades (pequenos avanços e ligeiros 
recuos), foi realizado sobre o império de sedimentos finos, de tal modo que o chamado processo de "progradação" não pôde ficar registrado por feixes de restingas arenosas costeiras. Mesmo assim, os campos submersíveis, o lago Ararí, os igarapés e gamboas, com seus diferentes tipos de cobertura vegetal e hidroecossistemas, apresentam-se sob a forma de um mosaico complexo, sob condições climáticas quentes e muitos chuvosas. Fato que se repete, talvez com menor complexidade, nos espaços ecológicos diferenciados do delta do Araguarí. Identicamente, os deltas de fundo de estuário do baixo Tocantins, frente à baía das Bocas, e o tampão deltaico interno de Breves incluem sedimentos fluviais e aluviais múltiplos, responsáveis por suportes geo-ecológicos diferenciados.

\section{Disponibilidades bibliográficas e recuperação de conhecimentos}

$\mathrm{Na}$ imensa bibliografia referente ao domínio fitogeográfico amazônico, pode-se obter informes genéricos - em geral taxionômicos - de interesse indireto para a caracterização dos ecossistemas regionais. Entretanto, para quem pretenda recuperar conhecimentos preexistentes, a favor da temática dos mosaicos de ecossistemas ocorrentes em uma área de 4,2 milhões de quilômetros quadrados, o acervo bibliográfico se apresenta como um "cipoal", tal a sua fragmentaridade e amarração a óticas exclusivamente florísticas ou fito-fisionômicas. Falta, sobretudo, na maior parte das vezes, aquela interdisciplinaridade exigida pelo conceito de ecossistema no que tange ao suporte ecológico representado pelos solos, hidrologia e dinâmica climática. Por outro lado, a lista de espécies registradas diz respeito a espaços ecológicos muito amplos, sendo muito raras as tentativas de levantamentos da composição fito-biótica pelo método dos quadrantes. Até mesmo em casos flagrantes de vegetação relicto ou mini-refúgios, existe uma grande míngua de pesquisas detalhadas que atendam às exigências do tratamento ecossistêmico - trate-se das cactáceas existentes nas encostas rochosas dos morrotes de Mucajaí, da vegetação híbrida das íngremes barrancas de abrasão fluvial de Monte Alegre ou das diferentes floras, ora arbustivas, ora composta de minirefúgios de cactáceas, existentes em suportes ecológicos de solos metalogênicos. Tendo em vista, sempre, que o tamanho do espaço não elimina a individualidade dos ecossistemas.

De qualquer forma, é extremamente útil rever o estoque bibliográfico disponível sobre a florística regional ou sub-regional da Amazônia vista em seu todo sul-americano. Nesse sentido, a bibliografia que acompanha a presente comunicação constitui um esforço seletivo, várias vezes apurado, para registro dos trabalhos taxionômicos essenciais sobre a Hyloea de Humboldt ou a Naiades de Martius.

A Alexander von Humboldt devemos a noção de zonação altitudinal da vegetação, que continua sendo básica para o entendimento das variações sofridas pela composição florística dos ecossistemas amazônicos, quer se considere a região cisandina, a serra dos Carajás ou as serranias florestadas orientais de Roraima e seus prolongamentos ao norte do Amazonas. Mas, em termos da Amazônia 
brasileira, tudo começou com o extraordinário e prolongado esforço de Carl Friedrich Philipp von Martius, em sua Flora Brasiliensis, dirigida sucessivamente por ele próprio (1840-1868), em colaboração com Endlicher (1840-1849), Eichler (1949-1887) e Urban (1887-1906), envolvendo contribuições de mais 65 botânicos. Como não podia deixar de ser, a Amazônia ficou muito bem representada nessa monumental obra, de iniciativa de Martius, considerada "esteio de toda a botânica sistemática brasileira", no dizer de Mário Guimarães Ferri (1979-80).

Entrementes, há que registrar o fato de que a primeira fase de identificação de componentes da vegetação amazônica, em território brasileiro, é uma herança - de uma muito longa história de observações empíricas - dos povos indígenas, que habitaram a região por alguns milhares de anos. Nesse sentido, a preponderância dos termos de origem tupi-guarani é esmagadora. Trata-se da língua mais abrangente no reconhecimento das plantas que compõem a flora geral da Amazônia e, ao mesmo tempo, é aquela que ocupa o maior e mais contínuo espaço nas terras amazônicas, onde ocorrem as mais diferentes combinações de espécies nativas. Além do que, é a toponímia que passou o maior número de informes genéricos ou pragmáticos para a cultura popular da população cabocla da Amazônia, representando assim um importante legado da medicina indígena para os homens isolados e marginalizados nas solidões territoriais da Hyloea.

O certo é que, nos dias de hoje, quando o índio ou caboclo - vivente na beira de rios, riozinhos ou igarapés, borda de lagos, igapós ou "furos" - serve de guia para pesquisadores de botânica ou zoologia, ele transmite informes e terminologia ameríndia, elaborada ao longo de milênios. De tal maneira, o conhecimento acumulado foi basicamente experimental, em termos de aplicações e descoberta de princípios ativos de diferentes validades. Algumas experiências com o uso de certas plantas foram letais ou incomodantes; outras vezes, porém, bemsucedidas ou salvadoras.

Os estudos de etno-ciências aplicados à Amazônia brasileira possibilitaram a identificação de um valor nitidamente ecológico em muitos termos de origem tupi. A expressão caatinga, por exemplo (hoje abandonada para evitar confusões com o ambiente de grande domínio semi-árido do Nordeste seco), alude às faixas de vegetação arbustiva ou sub-arbustiva esparsa, estabelecidas em manchas ou corredores de areia branca, estéril para suporte ecológico de matas. E, graças a um excelente estudo de Darrel Posey, pode-se saber que indígenas do Brasil tinham uma noção empírica, porém integrada, de todos os compartimentos rasos de uma planície de inundações, até os setores brejosos da várzea dominado por gramíneas, caracterizando a sua rampa ascendente florestada, até passar ao baixo terraço ou à base das vertentes de florestas de "terra firme".

Em função dos conhecimentos obtidos pelos estudos etno-botânicos, é possível rever a seqüência das fases de pesquisas e observações científicas ou empíricas, de interesse para aplicação do conceito de ecossistemas, ao vasto território amazônico, visto no seu todo espacial e altitudinal. Numa primeira aproxi- 
mação, com base em uma exaustiva revisão das bibliografias disponíveis, identificamos a seguinte sucessão de fases, as quais se iniciam por um longo período empírico e pragmático de observações, passando a diferentes períodos racionais, ainda uma vez entranhados de grande pragmatismo.

- Fase indígena, predominantemente tupi, parcialmente aruaque. Desenvolvimento lento e prolongado: alguns milênios. Identificação empírica e pragmática da maior parte do universo florístico da Amazônia: vegetação arbórea e arbustiva, cipós e ervas. Seleção de plantas medicinais que até hoje são utilizadas parcialmente pela medicina popular amazônica e brasileira. Identificação de madeiras e palmas para construções rústicas e ecológicas. Grande acuidade no reconhecimento de alguns padrões ecológicos integrados, sobretudo nas planícies aluviais e eventuais formações abertas, do tipo psamobiomas.

- Fase da conquista lusitana da Amazônia, com forte arrasamento físico e cultural de populações beiradeiras do vale, desde Marajó até o rio Negro e Solimões (séculos XVII e XVIII). Paradoxalmente, por iniciativa de missões religiosas, houve um sensível processo de atenuação das investidas bélicas contra as populações indígenas regionais, acompanhado de uma recuperação parcial dos conhecimentos indígenas regionais.

Em uma segunda fase, que se estendeu pela segunda metade do século XVII e pelo século XVIII, registram-se as observações do padre Cristobal de Acuña no retorno da grande viagem pioneira de Pedro Teixeira de Belém a Quito, publicadas em Madri (1641), e as anotações de viagem de Charles Marie de La Condamine (1743), o qual, como subproduto de suas pesquisas astronômicas, narrou os percalços de sua grande viagem oeste-leste, incluindo fatos da conjuntura física, biótica e humana da Amazônia brasileira, nos meados dos anos 1700 . Esse período termina bruscamente, em uma transição complexa, com as viagens e investigações científicas de Alexandre Rodrigues Ferreira.

A próxima fase envolve as viagens e pesquisas botânicas de Karl Frederich Philipp von Martius (1817-1820), que, após entrar em contato com as selvas equatoriais da Amazônia, tomou a decisão de estudar as palmeiras do Brasil e as plantas criptogâmicas, para depois iniciar sua contribuição máxima à botânica brasileira, em um admirável trabalho coletivo, que não se interrompeu com a sua morte: a Flora Brasiliensis (1829-1906). Trata-se de uma empreitada científica destituída de personalismos, sucessivamente dirigida pelo próprio Martius, por Eichler e por Urban, e envolvendo a colaboração de 65 pesquisadores da área de botânica. Tendo feito itinerários de pesquisa e coleta em quase todo o Brasil, Martius adquiriu um excelente espírito comparativo, que lhe possibilitou a identificação pioneira da maior parte dos grandes domínios fito-geográficos do país. No que se refere especificamente à Amazônia - a Hyloea de Humboldt, a Naiades de Martius - outros grandes cientistas acrescentaram observações ao longo do 
século XIX: Bates, Walace, Henri, Olga Coudreau, Chermon de Miranda, Barbosa Rodrigues, João Alberto Maso, Stradelli, Bus-calioni e, sobretudo, Richard Spruce.

Após esse período marcado pela contribuição dos viajantes naturalistas e por algumas contribuições isoladas, segue-se a brilhante fase de pesquisas botânicas desenvolvidas pelo Museu Paraense Emílio Goeldi, por meio dos trabalhos de Jacques Huber, Adolpho Ducke, João Murça Pires e William Antônio Rodrigues. Antecedendo-se a qualquer universidade brasileira, o Museu Goeldi funcionou efetivamente como um centro de pesquisas e formação de pessoal nas áreas de história natural e etnografia, servindo de base e apoio para numerosos pesquisadores provenientes do exterior ou do próprio país. De sua atuação e performance nos campos da botânica, zoologia e etnologia, e de seu exemplo institucional, desdobraram-se outras instituições especializadas em Belém e Manaus, tais como o antigo Instituto Agronômico do Norte, o Instituto Evandro Chagas, a Embrapa/CPATU, o Instituto Nacional de Pesquisas da Amazônia e, mais recentemente, a Universidade Federal do Pará, a Fundação Universidade do Amazonas e a FioCruz da Amazônia (Manaus). O acervo de documentos, informes e exemplares de coleta acumulados no Goeldi representa uma das mais significativas contribuições para o estudo da composição dos ecossistemas naturais da Amazônia do grupo "Vegetação" no Projeto RADAM e RADAM-BRASIL - a fórmula encontrada para separar ciência básica de ciência aplicável, extremamente inteligente, porém de muito trabalho. Isso porque além de elaborar a sua parte para ser incluída junto com os capítulos de geologia, geomorfologia, solos e uso potencial do solo, os membros da equipe realizaram, em anexos, livros inteiros sobre "análise estatística de dados" por processos computacionais. Nesses anexos documentários, fizeram-se análises qualitativas e quantitativas do potencial madeireiro ofertado pelas florestas amazônicas, em termos das espécies características de cada sub-região estudada. Tratava-se de uma encomenda oficial que não podia ser negligenciada. Nos objetivos definidos para os anexos, falavase pragmaticamente no potencial madeireiro, nos fundamentos de uma política florestal em busca de um zoneamento dos tipos florestais sub-regionais e na avaliação básica para um plano de economia florestal. Tratava-se, enfim, de uma perigosa rede de objetivos econômicos, pois desacompanhada de um conjunto estratégico de medidas de proteção à biodiversidade e gerenciamento das atividades madeireiras. Nem todos os pesquisadores dos estudos básicos do Projeto RADAM/ RADAMBRASIL eram botânicos e taxionomistas. Nesse sentido, foi decisiva a colaboração dos especialistas do Museu Goeldi (João Murça Pires e William A. Rodrigues).

Um período à parte na história das pesquisas sobre a vegetação da Amazônia brasileira ficou vinculado ao "Levantamento de Recursos Naturais" do Projeto RADAM e prosseguido pelo Projeto RADAMBRASIL. Pelo fato de ter sido elaborado em um intervalo de tempo relativamente pequeno (1973-1983), no que se refere aos levantamentos fito-geográficos do universo espacial amazônico, 
a contribuição das pesquisas realizadas pelo RADAM e RADAMBRASIL tem um nível de abrangência excepcional. Nos primeiros 22 volumes do Projeto, existem informes que interessam às variações fitoecológicas, à composição botânica dos diferentes tipos de vegetação distribuídos pelo espaço total amazônico, além das primeiras abordagens sobre os ecossistemas regionais da região. Não se utilizou o conceito de ecossistema de Tansley (1935), mas se realizou em esforço válido para deslanchar pesquisas nessa direção. Dirigido desde o início por Henrique Pimenta Veloso e Luiz Góes Filho, envolveu uma numerosa equipe de engenheiros florestais, naturalistas, botânicos especializados e geógrafos, constituindo-se em uma oportunidade única para um aprendizado dirigido para jovens pesquisadores e para auto-revisão de cientistas experientes.

Independentemente da epopéia de pesquisas vinculadas ao uso de imagens de radar sob controle de campo (1973 a 1983), houve uma fase ininterrupta de estudos temáticos e pesquisas sobre o terreno, de importância para o reconhecimento dos ecossistemas naturais amazônicos. Foram cinqüenta anos de publicações, conduzidas por variadas óticas e técnicas complementares de trabalho. Nessa fase, sucederam-se trabalhos elaborados por Black, Tacheuchi, Prance, Sioli, Junk, Adis e Loureira. Tiveram continuidade com algumas novas contribuições de João Murça Pires, William Antônio Rodrigues e Paulo Cavalcanti, sobre frutos da Amazônia. Um grupo de botânicos, liderados por Manoela Silva, integrou-se ao estudo da serra dos Carajás, com ênfase na vegetação de solos litólicos e enclaves rupestres das cangas hematíticas (Rosa, Seco, Lobo, Liboa, Mesquita). É uma nova geração que desponta no Museu Goeldi e no INPA, descobrindo novos temas para a botânica amazônica.

Paralelamente a tudo isso, desenvolveram-se pesquisas modernas de solos, limnologia, correlações responsáveis por psamo-biomas, helo-biomas e rupestres biomas, e variações climáticas sub-regionais. As idéias novas introduzidas sobre a história vegetacional e as razões das aparentes anomalias na distribuição das espécies ou conjuntos de espécies e subespécies, explicadas pela “Teoria dos Refúgios”, contribuíram para reorientar e esclarecer diversas questões enigmáticas.

O aprimoramento dos estudos fito-fisionômicos, da lavra de botânicos e geógrafos, contribuiu para orientar futuros trabalhos interdisciplinares sobre a estrutura, composição e funcionalidade de ecossistemas. Ficou claro, sobretudo, que para a realização correta de tais pesquisas não é possível continuar fazendo monografias em "separado" de ordem geológica, geomorfológica, pedológica, hidrológica e climática. Nesse sentido, as excelentes contribuições especializadas sobre solos perderam muito de sua força devido ao peso metodológico ortodoxo e à ausência de uma percepção dos solos como tecidos ecológicos e suporte básico de ecossistemas.

A despeito de tais considerações, convém lembrar que a Amazônia brasileira recebeu bons estudos de solos desde Marbut e Manifold, Bramão, Day, Sakamoto, Klinge, Stumülelr Sombroek, Benema, Lúcio Salgado Vieira e Ítalo 
Cláudio Falesi, entre outros, por meio de trabalhos que vêm desde 1925 até 1964, culminando pela campanha dos pedólogos que trabalharam no RADAM e RADAMBRASIL (1973-1989).

Por último, convém assinalar que o advento de uma correta aplicação do conceito de ecossistema à Amazônia possibilitará um aprofundamento da abordagem integrada dos fatos fisiográficos e bióticos, ao par com uma nova forma de ver os diferentes tipos de interferência dos processos antrópicos sobre os sistemas ecológicos herdados da natureza. Trata-se de uma temática de grande valor para prever impactos provocados por leis inconseqüentes ou por ações criminosas de pessoas ou grupos autoritários e insensíveis.

\section{Bibliografia}

Trabalhos gerais. História da Botânica e Ecologia no Brasil. Bibliografias.

AB'SABER, Aziz Nacib. "Ecossistemas Continentais" em Záliokacowicz e E.M. Oliveira (coord.). Relatório da qualidade do meio ambiente (Brasília: Sema).

ANDRADE LIMA, Dárdano. Atlas Nacional do Brasil (Rio de Janeiro: Fundação Brasileira de Geografia e Estatística, 1960).

AUBRÉVILLE, A. Étude écologique des principales formations forestière du Brásil (Nogent Sur-Marne, Seine: Comtre Technique Forestier Tropical, 1961).

BASTOS, A. Miranda. Contribuição ao conbecimento da floresta amazônica. Anais do $14^{\circ}$ Congresso da Sociedade Botânica do Brasil (1963).

BEARD, J.S. "The Classification of Tropical American Vegetation Types", Ecology, vol. 36, n' ${ }^{\circ} 1,1955$, pp. 89-100.

BOHRER, C.B. de A. e GONÇALVES, L.M.C.G. "Vegetação Amazônica" em Geografia do Brasil, vol. 3, Região Norte (Rio de Janeiro: IBGE, 1991). pp. 137-168. [Contém a bibliografia do Projeto RADAM sobre regiões fitoecológicas da Amazônia.]

BUSCALIONI, Luigi. Una escursione botanica nell' Amazonia (Roma: Bol. dei Soc. de Geogr. Italiana, 1901).

CAVALCANTI, Paulo B. Frutos comestiveis da Amazônia, 2a ed. (Belém: Ed. Frahia Neto, 1976). [Edição revista e ampliada em 1988 pelo Museu Paraense Emílio Goeldi, Belém.]

CONSELHO NACIONAL DE PESQUISAS IBBD/INPA. Amazônia: bibliografia 1614 - 1962 (Rio de Janeiro: CNPq/IBBD/INPA, 1963).

COSTA PEREIRA, José Veríssimo. "A Geografia no Brasil” em Azevedo, Fernando de (org. e diretor) As ciências no Brasil, vol. I (São Paulo: Ed. Melhoramentos, 1954-55), pp. 315-412.

DUCKE, A. e Black, G.A. Phytogeographical notes on the Brazilian Amazon. Anais da Academia Brasileira de Ciências, vol. 25, $\mathrm{n}^{\circ}$ 1, pp. 1-46 (Rio de Janeiro: março de 1953).

. "Notas sobre a Fitogeografia da Amazônia Brasileira", Bol. Tecn. Inst. Agron. do Norte, $\mathrm{n}^{\circ} 29$, pp. 3-62 (Belém: 1954).

EITEN, George. Classificação da vegetação do Brasil (CNPq: 1983). [Ilustrado] 
EITEN, George. Natural Brazilian vegetation types and their causes. Anais da Academia Brasileira de Ciências, "Simpósio Internacional sobre Ecologia e Agricultura Sustentável nos Trópicos”, vol. 64, Supl. 1, pp. 35-65 (3-6 de fevereiro de 1992).

FERRI, Mario Guimarães. "A Botânica no Brasil” em Azevendo, Fernando de (org. e diretor) As ciências no Brasil, vol. II, (São Paulo: Ed. Melhoramentos,1954-55), pp. 149-200.

"História da Ecologia no Brasil" em Ferri, M.G. e Motoyama, S. (coord.) História das ciências no Brasil, vol. 2 (São Paulo: Edusp/EPU/CNPq, 1980), pp. 307-340.

"História da Botânica no Brasil" em Ferri, M.G. e Motoyama, S. (coord.) História das ciências no Brasil, vol. 2 (São Paulo: Edusp/EPU/CNPq, 1980), pp. 33-38.

FITTKAU, E.J. Esboço de uma divisão ecológica da região amazônica, Symp. Biol. Trop. Amaz., pp. 363-372 (Florência \& Letícia: 1969).

FITTKAU, E.J., Illies, J., Klinge, H., Schwabe, G.H. e Sioli, H. Biogeography and ecology in South America, 2 vols (1968-69).

GARCIA, Rodolfo. "História das Explorações Científicas” em Diccion. Histr. Geogr.e Etnogr. do Brasil, edição comemorativa do $1^{\circ}$ Centenário da Independência (Rio de Janeiro: Inst. Histor. e Geogr. Brasileiro, 1922), pp. 856-910.

GLEASON, Henry Allan. Studies on the flora of northern South America, Bull of the Torrey Botanical Club, vols. 51,53-54,56-57 (Nova York: 1924-1931).

GOLLEY, F.B. Tropical ecological systems: structure and function (Nova York: SpringerVerlag, 1975).

HEINSDIJK, D. e Bastos, A. de M. "Inventários florestais na Amazônia” em Boletim n. 6 (Rio de Janeiro: Min. Agr. (BR), Serviço Florestal, Setor de Inventários Florestais, 1963).

HUBER, Jacques. "Matas e Madeireiras Amazônicas” em Bol. do Museu Paraense Emílio Goeldi, nº 6, pp. 91-225 (Belém, 1910).

HÜECK, Kurt. As florestas da América do Sul, tradução de Hans Reichardt (Brasília: Ed. da Univ. de Brasília; São Paulo: Ed. Polígono S.A., 1972). [Tradução de Die Wälder Südamerikas (Stuttgart, 1966).]

IBAMA; Conservation International; INPA. Prioridades biológicas para la conservacion de la Amazonia: Workshop 90 Manaus (Washington, D.C.: Prod. Yb Conservation Internacional, dezembro de 1991).

IBGE; IBDF. Mapa de vegetação do Brasil, escala 1:5.000.000 (Rio de Janeiro: IBGE/ IBDF, 1988).

KUHLMANN, Edgar. "Vegetação: Região Norte" em Geografia do Brasil, vol. I (Rio de Janeiro: IBGE, 1977), pp. 59-94.

LE COINTE, Paul. Amazônia brasileira III: árvores e plantas úteis indigenas e aclimatadas, $2^{a}$ ed. (São Paulo: Ed. Nacional, 1947).

LOUREIRO, A.A. e Silva, M.F. da. Catálogo das madeiras da Amazônia, vol. 1, (Belém: SUDAM, 1968), pp. 103-136.

MAGNANINI, A. e Caimbra Filho, A.F. Bibliografia florestal brasileira. Anais $14^{\circ}$ Congresso da Soc. Botânica do Brasil, pp. 411-501. Manaus.

MASO, João Alberto. "Flora e Fauna Amazonense e Acreana", Revista da Sociedade de Geografia do Rio de Janeiro, vol. 19, no 10, pp. 209-224 (Rio de Janeiro: 1908). 
MURÇA PIRES, João. "Contribuição para a Flora Amazônica”, Boletim Técnico do Instituto de Agronomia do Norte, vol. 20, pp. 41-51 (Setembro, 1950). [Notas sobre a flora neotrópica IV.]

"Noções sobre ecologia e fitogeografia da Amazônia", Norte Agrônomo, vol. 2, nº 3, pp. 27-54 (Belém: julho 1957).

e Prance, G.T. "The Vegetation Types of the Brazilian Amazon" em G.T.

Prance e Lavejoy, T.E. Keyenvironments: Amazonia (Oxford: Pergamon Press, 1985), pp. 109-145.

NELSON, Bruce Walker. "Caracterização da Flora Amazônica por Satélite” em Pavan, C. (coord.) Uma estratégia latino-americana para a Amazônia, vol. 2, (1996).

. "Inventário Florístico na Amazônia e a Escolha Racional de Áreas Prioritárias para Conservação" em Val, A.L. et alii (eds.) Bases científicas para estratégias de preservação e desenvolvimento da Amazônia,. vol. 1, (Manaus: INPA, 1996), pp. 173-183.

PRANCE, Ghillean T. e Brown Jr., K.S. "The Principal Vegetation Types of the Brazilian Amazon" em Whitmore, T.C. e Prance, G.T. (eds.) Biogeography and quarternary history in tropical America" (Oxford: Clarendon Press, 1988), pp. 30.

PRANCE, G. T. "Notes on the Vegetation of Amazonia, III: The Terminology of Amazonian Forest Types Subject to Inundation", Britannia, vol. 31, nº 1, pp. 26-38 (1979).

PROJETO RADAM. Levantamento de recursos naturais, vols. I a 7 (Rio de Janeiro: Ministério das Minas e Energia, 1973-74).

PROJETO RADAM BRASIL. Levantamento de recursos naturais, vols. 8 a 22 (Rio de Janeiro: Ministério das Minas e Energia, 1975-83).

RIZZINI, C.T. Tratado de fitogeografia do Brasil (São Paulo: Hucitec/EDUSP, 1976).

RODRIGUES, Roberto M. A flora da Amazônia (Belém: CEJUP, 1989).

RODRIGUES, William A. "A Cobertura Florestal da Amazônia Brasileira" em Pava, Clodowaldo (coord.) Uma estratégia latino-americana para a Amazônia, vol. 2 (São Paulo: Memorial da América Latina, Mun. do Meio Ambiente, 1996). pp. 57-78.

SAMPAIO, Alberto José de. "Nomes Vulgares de Plantas da Amazônia", Boletim do Museu Nacional, n 10, pp. 3-69 (Rio de Janeiro, março/dezembro 1934).

SEIBERT, P. "Die vegetationsgebiete des Reiseweges von J. B. v Spix und C. Ph. v. Martius heutiger Sicht" em Fitkau, E.J. Fita (ed.) Fertschrift zu Ehren von Dr. Johann Baptist Ritter von Spix, Spixiana Supl. vol. 9, pp. 63-80 (1983).

SILVA, M.F., Lisboa, P.L.B. e Lisboa R.C.L. Nomes vulgares de plantas amazônicas (Brasília, Manaus: CNP/INPA, 1977).

SIOLI, Harold. “Okologie des Amazonas-Gebietes" em Fitkau et alii (eds.) Biogeography and ecology in South America, vol. 1 (1968), pp. 137-170.

. "Tropical Rivers as Expressions of their Terrestrial Environments" em Golley, F.B. e Medina, Ernesto (eds.) Tropical ecological systems (Nova York: Springer-Verlag, 1975).

SOUZA, Celso Gutemberg. "Solos: Amazonia" em Geografia do Brasil: região norte, vol. 3 (Rio de Janeiro: IBGE, 1991), pp. 123-136.

SOUZA, Gabriel Soares de. Esboço histórico sobre a botânica e a zoologia no Brasil: 1587 a 7 de setembro de 1922 (São Paulo: Soc. Impressora Paulista, 1929). [Publicado originalmente no jornal $O$ Estado de São Paulo em 7 de setembro de 1922, edição comemorativa do centenário da Independência.] 
SOARES, Lúcio de Castro. "Limites Meridionais e Orientais da Área de Ocorrência da Floresta Amazônica em Território Brasileiro", Revista Brasileira de Geografia, ano 15, $\mathrm{n}^{\circ}$ 1, pp. 3-122 (Rio de Janeiro: IBGE, 1953).

SOMBROEK, W.G. Amazon soil:areconnaissance of the soils of the Brazlian Amazon region (Wageningen: Center for Agricultural Publication and Documentation, 1966).

TAKEUCHI, M.A. "A Estrutura da Vegetação na Amazônia II: As Savanas do Norte da Amazônia", Boletim do Museu Goeldi, série Botanica, n 7, pp. 1-17 (Belém: 1960). "A Estrutura da Vegetação no Brasil I: A Mata Pluvial Tropical”, Boletim do Museu Goeldi, série Botânica, nº 6, pp. 1-17 (Belém: 1960).

"A Estrutura Vegetal na Amazônia III: A Mata de Campina na Região do Rio Negro", Boletim do Museu Goeldi, série Botânica, nº 8, pp. 1-13 (Belém: 1960).

ULE, Ernst Heirich Georg. "Beitrage zur Florader Hylaea nach den Sammlungen von Ulés Amazonas Expedition", Verhandlungen des Botanischer Vereins der Provinz Bradenburg, vol. 48 (117-208) e vol. (50/60.-91) (1906-8). vol. 49 (1907).

"Die Pflanzenformatione des Amazonas gebietes", Engler's Botan. Iabrb.,

VANZOLINI, Paulo Emílio. "A Contribuição Zoológica dos Primeiros Naturalistas Viajantes”, Revista USP, , no 30, pp. 190-238 (São Paulo: USP, junho-agosto de 1996).

VELOSO, Henrique Pimenta. Vegetação, Folha SC-22: Tocantins, vol. 4, (Projeto RADAM: 1974), pp. 26-29.

\section{Fundamentos Conceituais}

D'HOORE, J. "Pedological Comparison Between Tropical South America and Tropical Africa", African Soils, vol. 4, n 3, pp. 4-20 (1959).

DANSEREAU, Pierre. Biogeography (Nova York: Ronald Press, 1957).

FALESI, Ítalo Claudio. "O Estado Atual dos Conhecimentos sobre os Solos da Amazônia Brasileira”, Atas do Simpósio sobre a Biota Amazônica: Geociências, pp. 151-168 (Rio de Janeiro, 1967).

RAMADE, François. Écologie fondamentale (Paris: McGrawHill/Ediscience Intern., 1984). "Écosysteme" em Dictionnaire encyclopédique d'écologie e des sciences de l'environment" (Paris: Ediscience International, 1993), pp. 208-216.

FARNWORTH, E.G. e Golley, F.B. Fragile ecosystems: evaluation of research and applications in the neotropics. (Nova York, Heidelberg, Berlim: Springer-Verlag, 1974).

TANSLEY, A.G. "The Classification of Vegetation and The Concept of Development", Journal of Ecology, vol. 8, pp. 118-149 (1920).

. A.G. "The Use and Abuse of Vegetational Concepts and Terms" Ecology, $\mathrm{n}^{\mathrm{o}}$ 16, pp. 254-307 (1935).

VAN DYNE, G.M. (ed.) The ecosystem concert in natural resource management (Nova York: Academic Press, 1969).

WIENS, John A. (ed.) "Ecosystem Structure and Function”, Colloquia. Vol. 31 (1972).

WALTER, Heinrich. Vegetação e zonas climáticas: tratado de ecologia global, tradução de Anna Terzi Giosa e Hildegard T. Buckup (Ed. Pedag.: 1986). 
WALTER, Heinrich. "Die ökologischen Systeme der Kontinente (Biogeosphäre)" Prinzipien ibren Gliaderuna nüt Bej (Stuttgart, 1976).

WILSON, E.O. (ed.) Biodiversity (Washington, D.C.: Nut. Gcad. Press, 1988).

Obras gerais. Conhecimentos Acessórios. Pedologia. Geomorfologia. Biogeografia.

AB'SABER, Aziz Nacib. "The Paleoclimate and Paleoecology of Brazilian Amazonia" em Prance, G.T. (ed.) Biological diversification in the tropics (Nova York: Columbia University Press, 1982), pp. 41-59.

"A Teoria dos Refúgios: origem e significado" em Anais do $2^{\circ}$ Congresso Nacional sobre Essências Nativas, edição especial, vol. 4 (São Paulo: Instituto Florestal: março/abril, 1992), pp. 29-34.

Amazonia: do discurso à praxis (São Paulo: Edusp, 1994);

"As Bases do Conhecimento sobre Paleoclimas Modernos da Amazônia", Ciência Hoje, vol. 16, nº 93, pp. 1-3 (SBPC: 1993).

ABSY, M. Lúcia. A palynological study of Holocene sediments in the Amazon basin, tese (Universidade de Amsterdã: 1970).

"Dados sobre as Mudanças do Clima e da Vegetação da Amazônia durante o Quaternário”, Acta Amazônia, ano X, fasc. IV, pp. 1929-1930 (Manaus: 1980).

BIGARELLA, J.J. e Ferreira, A.M.M. "Amazonian Geology and the Pleistocene and the Cenazoic Environments and Paleoclimates" em Prance e Lovejoy (eds.) Key environments: Amazonia (Oxford: Pergamon Press, 1989).

Lima, D.A. e Richs, P.J. "Considerações a Respeito das Mudanças paleo-

Ambientais na Distribuição de Algumas Espécies Vegetais e Animais do Brasil”, Anais da Academia Brasileira de Ciências (1981).

BRAGA, P.I.S. "Subdivisão Fitogeográfica: Tipos de Vegetação e Inventário Florístico da Floresta Amazônica", Supl. da Rota Amazônica pp. 570-78 (1979).

BROW JR., Keith S. "Centros de Dispersão, Refúgios Quaternários e Conservação de Patrimônios Genéticos na Região Neotropical, Acta Amazônica, vol. 7, n 1, pp. 75137 (1979).

BROW JR., K. S. e Ab'Saber, A.N. "Ice-Age Forest Refuges and Evolution in the Neotropics: Correlation of Paleoclimatological, Geomorphological and Pedological Data with Modern Biological Endemism" Paleoclimas, $\mathrm{n}^{\circ} 5$ (São Paulo: IDEOG-USP, 1979).

CAMPBELL, D.G. et alii. "Quantitative Ecological Inventory of Terra Firme and Várzea Tropical Forest on the River Xingu", Brittania, n 38, pp. 369-393 (1986).

CHAPMAN, V.G. Marigwve vegetation (Vaduz, 1976).

DAEMON, R.F. e Contreiras, C.J.A. "Zoneamento Palionológico da Bacia do Amazonas" em $25^{\circ}$ Congresso Brasileiro de Geologia, vol. 3, pp. 79-92 (São Paulo: 1971).

DAVIS, E.W. e Yost, J.A. "The Ethnobotany of the Waorani of Eastern Ecuador", Botanical Museum Leaflets, $\mathrm{n}^{\circ}$ 29, pp. 159-217 (1983).

DESCAMP, M.J.P., Gasc, J., Lescire, J. e Sastre, C. "Études des Écosystèmes Guaijanais, II: Données Biogeographiques sur la Partie Orientale des Guyanes”, C.R. Biogéogr., $n^{\circ} 467$, pp. 55-82 (Paris, 1976).

EMILIANI, C. "Paleotemperature Analysis of the Caribbean Cores P6304-8 and P63049 and a Generalized Temperature Curve for the Past 425,000 years." 
EMILIANI, C. "Pleistocene paleotemperatures", Science, nº 168, pp. 822-825 (1970).

FAIRBRIDGE, Rhodes W. Effects of holocene climatique change on some tropical, pp. 528-556.

FITTKAU, E. J. et alii. "Substrate and Vegetation in the Amazon Region", Beriobto dor internationalen Symposien der Internationalen Vereinigung für Vegetationskunde, pp. 73-90 (Lehre, 1975).

"An Ecological Perspective of Species Diversity in an Amazonian", Research and Development, 3: 64-85 (Tübingen, 1975).

GOODLAND, R.J.A. e Irwin, H.S. "Amazonian Forest and Cerrado: Development and Environmental Conservation" em Prance, G.T. e Elias T.S. (eds.) Extinction is forever (Nova York: New York Botanical Garden, 1977), pp. 214-223.

HAFFER, Jüergen. "Speciation in Amazonian forest birds", Science, n ${ }^{\circ}$ 165, pp. 131$137(1969)$.

"Avian Speciation in Tropical South America", Nuttall Ormith Club, $\mathrm{n}^{\mathrm{o}}$ 14 (Cambridge, Mass., 1974).

"Pleistocene Speciation in Amazonian Birds", Amazoniana, vol. 6, n 2 , pp. 161-192 (1977).

"Distribution of Amazon forest birds", Bonn. Zool. Beitr., vol 29, pp. 38$79(1978)$.

"General Aspects of the Refuge Theory" em Prance, Ghillean T. Biological diversification in the tropics, cap. 2, (Nova York: Columbia University Press, 1982), pp. 6-24.

"Ciclos de Tempo e Indicadores de Tempos na História da Amazônia", Estudos Avançados, $\mathrm{n}^{\circ}$ 15, pp. 7-40 (São Paulo: IEA-USP, 1992).

HUECK, K. "Vegetationskarte von Sudamerika", Veg. Monogr. de unz Grossräume. Vol. II (Stuttgart: 1972).

JOURNAUX, André. “Geomorphologie des Bordures de L'Amerique: Modelé des Versants, Essai D'evolution Paleoclimatique", Bull. de l'Assoc. Geogr. Français, n ${ }^{\circ}$ 422/423, pp. 3-18 (Paris, 1975).

KLAMMER, G. "Über Plis-Pleistozäne Terrassen und Ibre Sedimente in Utere Amazonagebiet", Zeitsch, für Geomorph NF, vol. 15, n 1, pp. 62-106 (1971).

"Zür Jungquataren Reliefgeschichte des Amazonstalen", Zeitsch, für Geomorph NF, vol. 20, n 2, pp. 149-170 (1976).

Reliefentwicklung in Amazonbecken und plis-pleistozäne Bewegugen des Meerespiegels.- Zeitsch, für Geomorph NF, v. 22, nº 4, pp. 390-416 (1978).

KLINGE, H. "Padzol Soils in the Amazon Basin", Journ. Soil Scien., vol. 16, n 1, pp. 95-103 (1965).

MEGGER, C.B.J., Ayensu, E.S. e Duckworth, W.D. Tropical forest ecosystems in Africa and South America: a comparative review (Washington: Smithsonian Institution Press, 1973).

MÜLLER, P. e Schmithüsen, J. "Probleme der Genese südamerikkanischen Biota" em Festschn E. Gentz, pp. 109-122. (Deutsche Geogr. F. in der Welt von Haute, Kiel:1970).

NELSON, Bruce Walker. "Diversidade Florística de Exossistemas Amazônicos", Anais do $2^{\circ}$ Congresso Nacional sobre Essências Nativas, edição especial, Vol. 4 (São Paulo: Instituto Florestal: março/abril, 1992), pp. 29-34. 
PRANCE, Ghillean T. "The Origin and Evolution of the Amazon Flora", Interciência, $\mathrm{n}^{\mathrm{O}} 3$, pp. 207-222 (1978).

"Forest Refuges: Evidence from Wood Angiosperms" em Prance, G.T. (ed.) Biological diversification in the tropics (Nova York: Columbia University Press, 1982), pp. 137-157.

1985).

e Lovejoy, T.E. Key environments: Amazonia (Oxford: Pergamon Press,

SANTOS, João Orestes Schneider. "O Pantanal Setentrional e os Campos de Dunas da Amazônia Ocidental”, Simpósio Internacional do Quaternário da Amazônia, resumos (Unesco: FUA/QUA, 1992).

, Nelson, B.W. e Giovannini, C.A. "Leitos Abandonados de Grandes Rios:

Campos de Dunas quaternários", Ciência Hoje, vol. 16, n 33, pp. 22-25 (SBPC: 1997).

SIMPSON, B.B. e Haffer, J. "Speciation Patterns in the Amazonian Forest Biota", Ann. Ver. Ecol. Syst., vol. 9, pp. 497-518 (1978).

SIOLI, Harald. "Studies in Amazonian Waters", Atas do Simpósio sobre a Biota Amazônica: Limnologia, pp. 9-50 (Rio de Janeiro: 1967).

(ed.) The Amazon (Dordrecht: Dr. W. Junk Publs, 1984).

SOARES, Lúcio de. Amazônia (Rio de Janeiro: Conselho Nacional de Geografia, 1963), 341 pp., 65 figs.

SOMBROEK, W.G. Amazon soil (Wageningen: C.A.P.D., 1966).

SOUBIÈS, F. "Existence d'une Phase Sèche en Amazonie Brésilienne Datée par la Presence de Charbons dans les Sol: 6000-3000 Ans", Orston, Cahiers (B.P.) Geologie, vol. XI-1, pp. 133-148 (1980).

SUTTON e Chadwick (eds.) Tropical rainforest: ecology and management (1983).

TASTEVIN, C. "Nomes de Plantas e Animais em Lingua Tupy" em Ver. do Museu Paulista, $\mathrm{n}^{\circ}$ 13, pp. 687-764 (São Paulo, 1923) [e Vocabulário Tupy-Portuguez, 99.0599-686].

TRICART, Jean. Ecodinamica (Rio de Janeiro: Supren. IBGE, 1977) [Com numerosas referências às formações superficiais e às variações climáticas quaternárias da Amazônia.] "Aperçus sur le Quaternaire Amazonien", Rechs. Françaises sur le Quaternaire. INQUA. 1977. Supl. au Bull, AFEQ (1977), nº 50.

. "Conhecimentos sobre o Quaternario Amazônico", Paleoclimas, nº 6 (São Paulo: IGEOG-USP, 1979).

VAN DER HAMMEN, Theodor. "The Pleistocene Changes of Vegetation and Climate in Tropical South America", Journal of Biogeography, $\mathrm{n}^{\circ}$ 1, pp. 3-26 (1974).

VANZOLINI, Paulo Emílio. Zoologia sistemática e a origem das espécies (São Paulo: Instituto de Geografia-USP, 1970). [Teses Monogrs. nº 3].

VANZOLINI, Paulo Emílio."Paleoclimates, Relief, and Species Multiplication in Equatorial Forests" em Meggers, B.J., Ayensu, E.S. e Duckworth, W.D. (eds.) Tropical forest ecosystems in Africa and South America: a comparative review, (Washington: Smithsonian Institution Press, 1973), pp. 255-259.

. "Paleoclimas e Especiação em Animais da América do Sul Tropical", Assoc.

Bras. de Estudos do Quaternário, publicação avulsa, n 1 (São Paulo, 1986). 
VANZOLINI, Paulo Emílio. "Paleoclimas e Especiação em Animais da América do Sul Tropical”, Estudos Avançados, ano 6, nº 15, pp. 41-65 (São Paulo: IEA-USP, 1992). e Williams, E.E. "The Vanishing Refuges: A Mechanism for Ecogeographic Speciation", Papéis Avulsos de Zoologia, ano 34, no 23, pp. 251-255 (1981).

WITMORE, T.C. e Prance, G.T. (eds.) Biogeography and quaternary history in tropical America (Oxford: Clarendon Press, 1987).

Aziz N. Ab'Saber, geógrafo, e professor honorário do Instituto de Estudos Avançados da USP.

Texto publicado originalmente em inglês em Amazonia - Heaven of a New World (Rio de Janeiro: Editora Campus, 1998), coordenado por Maria de Lourdes Davies de Freitas, a quem a revista agradece ter autorizado a publicação da versão em português. 